\title{
NÍVEL TECNOLÓGICO E FATORES DE DECISÃO PARA ADOÇÃO DE TECNOLOGIA NA PRODUÇÃ̃O DE CAJU NO CEARÁ ${ }^{1}$
}

\author{
Sergiany da Silva Lima \\ Ahmad Saeed Khan \\ Patrícia Sales Lima ${ }^{4}$ \\ Lucas Antônio de Sousa Leite ${ }^{5}$ \\ Adriano Lincoln Albuquerque Mattos ${ }^{6}$
}

\begin{abstract}
Resumo: Este artigo investiga o processo de adoção tecnológica na cajucultura do Ceará. Para alcançar este objetivo, foi realizado um levantamento de dados junto aos produtores de caju do Ceará. Quanto à mensuração do nível tecnológico dos produtores, foram analisadas variáveis relacionadas com práticas do sistema de produção de caju. Adicionalmente, foram estimados coeficientes para as variáveis que influenciam a adoção de tecnologias por meio de um modelo de regressão Logit. Observou-se que as propriedades ocupadas com o caju-de-mesa têm a melhor tecnologia de produção, visto que utilizam $46,7 \%$ da tecnologia recomendada, enquanto as voltadas para a produção de suco e castanha usam apenas 36,4 e $30,1 \%$, respectivamente. $\mathrm{O}$ acesso ao crédito e os preços da castanha e do pedúnculo foram os principais fatores determinantes da adoção de tecnologias na cajucultura no Ceará.
\end{abstract}

Palavras - chave: cultura do caju, nível tecnológico, adoção tecnológica.

Recebido em: 24/09/09; Aceito em: 01/04/10.

2 Professor Substituto do Departamento de Teoria Econômica da Universidade Federal do Ceará. E-mail: segiany@yahoo.com.br

3 Professor Titular do Departamento de Economia Agrícola da Universidade Federal do Ceará e Bolsista do Conselho Nacional de Desenvolvimento Científico e Tecnológico (CNPq). E-mail: saeed@ufc.br

4 Professora adjunta da Universidade Federal do Ceará. e Bolsista do Conselho Nacional de Desenvolvimento Científico e Tecnológico (CNPq). E-mail: pvpslima@ufc.br

5 Chefe geral da Embrapa Agroindústria Tropical e pesquisador da Empresa Brasileira de Pesquisa Agropecuária. E-mail: lucas@cnpat.embrapa.br.

6 Analista A da Embrapa Agroindústria Tropical e pesquisador, atuando nas áreas da economia e extensão tecnológica. E-mail: adriano@cnpat.embrapa.br. 


\section{Introdução}

No Brasil, onde há maior interesse pelo aproveitamento do pedúnculo floral do caju ${ }^{7}$, são encontradas diversas opções de mercado mediante o emprego de técnicas industriais. Dentre essas opções, a de maior significado econômico é a fabricação do suco integral de caju, que consome grande quantidade do falso fruto do caju entre os demais subprodutos da fruta. O pedúnculo de caju tem sua cadeia produtiva estendida a diversas variedades de doces, refrigerantes e ração animal para bovinos e aves (BARROS, 2002). O suco de caju integral é o subproduto da cajucultura de maior relevância econômica da região, devido à grande aceitação nos mercados local e nacional (CAJUCULTURA, 2008).

Entretanto, conforme Leite e Paula Pessoa (2002), a representatividade do suco de caju no volume das exportações brasileiras de sucos é muito pequena. Em vista disso, os institutos de pesquisas e as universidades vêm despendendo esforços para estudar formas alternativas de beneficiamento do pedúnculo, a exemplo do pó desodorizado, da fibra para o uso em panificação, do suco clarificado desodorizado concentrado e do suco gaseificado. O objetivo da diversidade de formas de aproveitamento do pedúnculo compreende parte de um trabalho de promoção do agronegócio do caju, ainda muito dependente das exportações da amêndoa da castanha-de-caju (ACC) (LEITE e PAULA PESSOA, 2002).

A perda de competitividade das exportações brasileiras de ACC, devido especialmente ao alto número de castanhas quebradas, comparativamente à Îndia e ao Vietnã, reflete a defasagem do setor (MENDONÇA et al., 2009). No entanto, nos últimos tempos, o caju vem conseguindo angariar parcelas adicionais do mercado brasileiro de frutas frescas, devido à "padronização do produto com as plantas clonadas e o domínio da cadeia de frios" (LEITE e PAULA PESSOA, 2002). Filgueiras e Alves, apud

Também conhecido como caju, maçã do caju, falso fruto ou pseudofruto (BARROS, 2002). 
Morais et al. (2002), afirmaram que o consumo do pedúnculo de cajueiro anão-precoce vem crescendo, a cada safra, no mercado de frutas frescas, ou caju-de-mesa, tanto pela consolidação de mercados tradicionais como pela abertura de novos mercados.

Desse modo, tendo em vista a expansão dos mercados derivados do caju e o seu potencial de produção, espera-se que o valor socioeconômico do pedúnculo ultrapasse, rapidamente, a importância conferida à castanha, mesmo se limitando, quase exclusivamente, ao mercado doméstico dos subprodutos do pedúnculo (BARROS, 2002).

Segundo Damasceno Júnior e Bezerra (2002), a cajucultura gera, no Brasil, cerca de 300 mil empregos diretos e indiretos, e, só no ano de 2007, o Brasil exportou US\$225.195 mil (FAO, 2010). Segundo o IBGE (2006), 98,6\% da produção nacional de caju estão inseridos no Nordeste brasileiro, e a maior parte está situada no estado do Ceará. Dessa forma, com o desenvolvimento da cajucultura, o semi-árido nordestino e, especialmente, o Estado do Ceará seriam os maiores beneficiados. Contudo, as particularidades intrínsecas aos mercados que compreendem a cajucultura cearense indicam que as práticas de preços baixos, pagos ao produtor nos diversos mercados, assim como a limitação do comércio do caju-de-mesa, são alguns dos principais responsáveis pelo atraso tecnológico dos pomares de cajueiros.

Nesse preâmbulo, destaca-se o poder oligopsônico do segmento agroindustrial do suco e da castanha-de-caju no estado do Ceará, que ditam os preços ao seu favor e em prejuízo ao produtor rural (FIGUEIRÊDO JUNIOR, 2006). A única opção de mercado, cuja prática de preço gera alguma vantagem para o produtor rural, é o do caju in natura para o consumo de mesa. Não obstante, trata-se de um mercado ainda muito restrito e de exigência incompatível com os padrões de produção cearense. Oliveira (2002), em apoio a essa defesa, descreve o modelo de produção da cajucultura cearense como de plantio heterogêneo e exploração extrativista. Com relação a esse aspecto, Araújo, apud Martins e Costa (2005), atribuiu a crise da cajucultura ao baixo nível 
tecnológico no processo produtivo, bem como aos problemas de comercialização.

Conforme Paula Pessoa et al. (2000), a cajucultura é uma atividade rentável, desde que sejam utilizadas tecnologias recomendadas. $\mathrm{O}$ avanço tecnológico no meio agrícola vem sendo estudado com o propósito de melhorar o desempenho das unidades produtivas. Assim, a identificação dos fatores responsáveis pela adoção de tecnologias modernas vem constituindo preocupação central da agricultura moderna, para que se possa chegar a um produto de boa qualidade, com reflexos positivos na lucratividade dos empreendimentos rurais (MONTE e TEIXEIRA, 2006).

Por essas razões, o objetivo desta pesquisa é identificar o nível tecnológico da atividade produtiva e descrever os principais fatores responsáveis pela adoção de tecnologia na cajucultura no estado do Ceará. No tópico seguinte, será apresentado o método empregado pela pesquisa, com o esboço dos índices de tecnologias utilizados e do modelo econométrico ajustado. Em seguida, será exibido o tópico de análise dos resultados e, finalmente, as considerações finais do estudo.

\section{Metodologia}

\subsection{Média do Índice Geral de Tecnologia das Propriedades (IGM)}

A média do índice geral de tecnologia (IGM ) do cultivo do cajueiro envolveu etapas do processo produtivo, do preparo do terreno à póscolheita da fruta. Para cada propriedade $j$, foram determinados oito índices tecnológicos representados pelo subscrito $b$, como segue:

$$
I_{b j}=\sum_{r=1}^{k} \frac{M r}{S b},
$$


$\operatorname{com} r=1,2, \ldots, k$.

em que $I_{b j}$ é o índice da tecnologia, $b$ na propriedade $j ; r, r$-ésima variável referente à tecnologia $b ; \mathrm{e} \frac{M r}{S b}$, uso efetivo da tecnologia como proporção do seu uso potencial.

Com os $I_{b j}$ obtidos, o índice de tecnologia geral da propriedade $j\left(I G_{j}\right)$ foi estabelecido por

$$
I G_{j}=\frac{1}{v} \sum_{b=1}^{v} I_{b j}
$$

Com $\mathrm{b}=1, \ldots$, v é $v$ igual ao número de tecnologias.

A importância da tecnologia $b$, na propriedade $j$, foi definida por

$$
I_{b}=\frac{1}{n} \sum_{j=1}^{n} I_{b j} .
$$

Entendendo $I_{b}$ como o nível de adoção das tecnologias nas propriedades rurais por segmento de mercado e $n$ como o número de propriedades por segmento de mercado ${ }^{8}, I_{b}$ é dividido e interpretado, como sugeriu Miranda, apud Oliveira (2003):

$0,75<I_{b} \leq 1,00$ : conjunto de propriedades $j$ que têm padrão tecnológico

\footnotetext{
Os segmentos de mercados analisados foram caju para suco, caju-de-mesa e castanha-de-caju.
} 
I ou ótimo; $0,50<I_{b} \leq 0,75$ : conjunto de propriedades $j$ que têm padrão tecnológico II ou bom; $0,25<I_{b} \leq 0,50$ : conjunto de propriedades $j$ que têm padrão tecnológico III ou regular e $0,00 \leq I_{b} \leq 0,25$ : conjunto de propriedades que têm padrão tecnológico IV ou insuficiente.

Definido o $I G_{j}$ das propriedades, o $I G M$ foi determinado por

$$
I G M=\frac{1}{n} \sum_{j=1}^{n} I G_{j} .
$$

Foi definida, ainda, a média do índice geral de tecnologia do grupo total de propriedades s, $\left(\right.$ IGM $\left._{s}\right)$ para expressar o nível geral de tecnologia do sistema de produção do caju, englobando os três segmentos de mercado, analisados conjuntamente.

$$
I G M_{s}=\frac{1}{s} \sum_{j=1}^{s} I G_{j} .
$$

Sendo $j=1,2, \ldots, n, \ldots, s$, em que s representa o número total de produtores rurais.

A participação no IGM de cada tecnologia, por modelo de exploração do caju, foi obtida por meio da seguinte equação:

$$
C b=\frac{1}{v} \cdot\left(\frac{1}{n} \cdot \sum_{j=1}^{n} \frac{M b_{j}}{S b}\right),
$$

em que $C b$ representa a contribuição da $b$-ésima tecnologia na formação do $I G M ; M b_{j}$, escore da tecnologia $b$ na propriedade $j ; \mathrm{e}$ $S b$, escore máximo da tecnologia $b$. 


\subsection{Função Distribuição Acumulada Logística Padrão (Logit)}

Segundo o critério de interpretação do nível de adoção de tecnologia desta pesquisa, ou o proprietário adota tecnologia adequada para produção, tendo $Y=1$, ou não o faz, tendo $Y=0$. Esse tipo de análise é desenvolvida mediante o emprego dos modelos de resposta binária, que, entre os mais conhecidos, se destacam a função distribuição acumulada logística padrão (Logit), a função distribuição acumulada normal padrão (Probit) e o modelo com variável dependente limitada (Tobit). Conforme Gujarati (2000), a decisão pelo modelo apropriado é arbitrária e de conveniência matemática.

Aldrich e Nelson (1997), apud Pinho (2007), concordaram com a arbitrariedade da decisão. No entanto, há a tese de que "[...] o uso de distribuições com caudas mais pesadas tem sido preconizado em alguns modelos quando as variáveis distanciam-se da normalidade, como é o caso de muitas varáveis econômicas" (PINO; MORETTIN, 1993 apud PINHO, 2007, p. 49). Nesses termos, a opção de modelo, nesta pesquisa, foi pelo Logit, devido à maior probabilidade de acerto encontrado pelo referido modelo. Conforme Greene (1997), a função de probabilidade Logit é descrita, como segue, na equação 7.

$$
\operatorname{Pr}[Y=1 / X]=L\left(\beta^{\prime} X\right)=\frac{1}{1+e^{-\left(\beta_{0}+\beta_{1} X_{1}+\ldots+\beta_{k} X_{k}\right)}}
$$

A variável dependente, "adtec", significa adoção de tecnologia, que terá valor 0 (zero), quando a plantação de cajueiro utilizar menos de $35 \%$ da tecnologia recomendada, e 1 (um), quando a plantação empregar, no mínimo, 35\% do recomendo. A divisão desse índice em igual ou superior a 0,35 e menor que 0,35 , para representar a adoção, ou não, de tecnologia, foi definida pelo valor mediano da série de índices, obtida para equilibrar o número de respostas 1 e 0 . 
As demais variáveis tomadas como independentes, "areagiga", "areapreco", "acecredt", "cjatvdprinc", "associação", "escolaridade”, "p_cast" e "p_pedun", significam, respectivamente, hectares de cajueiro gigante; hectares de cajueiro precoce; acesso ao crédito que pode ser $\operatorname{sim}(=1)$ ou não $(=0)$; estabelecimentos que têm no caju sua principal atividade, que também se põe como $\operatorname{sim}(=1)$ ou não $(=0)$; produtores de caju organizados em associações cujas possibilidades, do mesmo modo, são sim (=1) ou não $(=0)$; nível de escolaridade com distribuição de escores, conforme o grau de estudo; nível de preço da castanha e nível de preço do pedúnculo, medido em centavos de real por quilograma.

O cálculo do efeito marginal foi obtido pela derivada da função de distribuição acumulada (PINHO, 2007):

$$
\frac{\partial L\left(\beta X_{i}\right)}{\partial x_{i k}}=\gamma(\beta \backslash X) \cdot \beta_{k}
$$

$\mathrm{Na}$ medição do ajuste geral da regressão logística foi empregado o $R^{2} \log$ it , como descrito em Hair et al. (2005).

$$
R^{2}{ }_{\log i t}=\frac{-2 L L_{\text {nulo }}-\left(-2 L L_{\text {modelo }}\right)}{-2 L L_{\text {nulo }}}
$$

O teste de significância (Wald Test) foi descrito por Greene (1997):

$$
W=(R \hat{\beta}-q)^{\prime}\left\{R(\text { Est.Asy.Var }[\hat{\beta}]) R^{\prime}\right\}^{-1}(R \hat{\beta}-q) \cdot
$$

A estatística LR foi calculada, como ilustra Greene (1997),

$$
L R=-2\left(\ln L_{R}-\ln L\right) .
$$


O teste de heteroscedasticidade seguiu a equação de Davidson e Mackinnon, disposta no Soft Eviews 6:

$\operatorname{Var}\left(e_{i}\right)=\exp \left(z_{i}^{\prime} \gamma\right)^{2}$

O teste de multicolinearidade utilizou-se dos coeficientes de Pearson e Spearman's.

\subsection{Fonte de dados e características do processo de coleta}

Os dados da pesquisa foram coletados pela aplicação de 163 questionários, segundo modelo aleatório simples, junto aos produtores de caju dos principais pólos de produção de caju do Ceará. O número foi considerado representativo de uma população de 11.751 produtores. A delimitação geográfica utilizada foi definida com o auxílio do IBGE, conforme o mapeamento dos municípios com áreas plantadas de cajueiro igual ou superior a 5.000 hectares, situadas num raio até $50 \mathrm{~km}$ das empresas de maior participação na indústria de suco de caju do Ceará (IBGE, 2008).

\section{Resultados e discussão}

Na seção 3.1., são descritas as características socioeconômicas dos produtores rurais, relevantes para descrição do processo de adoção tecnológica, segundo participação nos mercados de caju para suco, cajude-mesa e castanha-de-caju. A seção 3.2 descreve o nível médio de tecnologia $I G M$ e $I G M_{s}$, identificado nos pomares de cajueiros analisados.

Essa seção é responsável, ainda, pela apresentação da contribuição de cada tecnologia $\mathrm{Cb}$ na formação do $I G M$ em cada modelo de exploração do caju analisado, conforme o segmento de mercado a que 
pertence. As principais tecnologias e as de menor importância na formação do $I G M$ expõem as potencialidades e dificuldades do setor.

Na seção 3.3. são identificados os fatores de maior influência na probabilidade de adoção tecnológica e as características inerentes a cada sistema produtivo, relevantes para explicação das estimativas de adoção tecnológica. A seção 4 compreende as conclusões mais importantes da descrição dos resultados deste estudo.

\subsection{Características socioeconômicas dos produtores de caju por participação de mercado}

Há elevada gama de produtores rurais na cajucultura que não conseguiram chegar ao ensino fundamental, e muitos dos produtores entrevistados, que iniciaram os estudos, não conseguiram terminar o ensino fundamental. Numa análise geral dos indicativos relacionados com educação dos produtores rurais, observou-se baixo nível de interesse pela busca de instrução escolar?.

Tabela 1 - Frequência relativa (Fr) das características socioeconômicas relevantes para descrição do processo de adoção tecnológica nas propriedades de cajueiro dos segmentos do mercado de caju para suco, caju-de-mesa e castanha-de-caju (\%)

\begin{tabular}{l|ccc}
\hline \multirow{2}{*}{ Características socioeconômicas } & \multicolumn{3}{|c}{ Segmento } \\
\cline { 2 - 4 } & Suco & Mesa & Castanha \\
\hline Analfabeto/Fundamental incompleto & 80,9 & 72,8 & 78,6 \\
1 a 4 trabalhadores da família & 54,6 & 45,5 & 69,0 \\
Comprador de pedúnculo (intermediário) & 76,4 & 90,9 & 0,0 \\
Comprador de castanha (intermediário) & 74,5 & 72,7 & 95,2 \\
Cajucultura (principal fonte de renda) & 85,5 & 90,9 & 78,6 \\
\hline
\end{tabular}

Fonte: Dados da pesquisa.

Durante as entrevistas, a principal argumentação dos agentes era de que a escola era distante, ou casou, ou engravidou, ou precisou trabalhar. 
A principal fonte de trabalho utilizada na produção de caju provém, basicamente, da unidade familiar, característica básica das pequenas propriedades. A mão-de-obra contratada de forma permanente responde por muito pouco da força de trabalho utilizada nos pomares. A maioria das propriedades estudadas dispõe de 4 trabalhadores com tempo integral disponível para os pomares de cajueiros, nos períodos de safra e entressafra, e até 5 trabalhadores aproveitados apenas nas fases de alta demanda pela cultura. Durante todo o ano, os pomares de cajueiro dependem, unicamente, das condições naturais do ecossistema do semiárido, característicos do Nordeste brasileiro (MOURA, 1998, apud PAULA PESSOA et al., 2000). Nessas condições, a exploração da cajucultura é realizada, quase exclusivamente, em regime extrativista, o que condiz com a tese de Oliveira (2002).

O comércio do produto da cajucultura limitou-se, por muito tempo, à comercialização da castanha. A produção industrial do suco de caju e, mais recentemente, o mercado do caju-de-mesa estimularam essa atividade econômica, garantindo maior aproveitamento do caju e oferecendo melhores oportunidades de mercado. No entanto, a reclamação geral do setor estabelece-se em torno dos baixos preços de compra, definidos, principalmente, no âmbito da indústria de suco e castanha. De acordo com dados do IBGE (2008), em referência ao censo de 1996, mais de 50\% dos produtores de caju, nessa época, dependiam do transporte do intermediário para o escoamento da produção. Essa prática ainda continua bastante atual, ao apresentar a frequência do intermediário como principal agente comprador do produto nos três segmentos de mercado analisados.

A diversificação de consumo da castanha e a maior resistência ao pedúnculo constituem características que poderiam favorecer melhores oportunidades de venda. Contudo, assim como o pseudofruto do caju, a castanha depende, em sua maior parte, da comercialização com intermediários, sendo submetida à mesma imposição de preços baixos. Além disso, a capacidade de processamento da castanha no Ceará, de 
$69 \%$ da produção nacional, similarmente à indústria do suco, é limitada a sete empresas ${ }^{10}$ (FIGUEIRÊDO JUNIOR, 2006).

A maioria dos produtores de caju tem nessa atividade sua principal fonte de renda. Mesmo assim, essa característica não necessariamente constitui um determinante para modernização das plantações, como será visto a seguir. Em linhas gerais, o mercado do caju de mesa compreende a parcela de produtores que têm na cajucultura o item mais importante do rendimento familiar, seguido, em escala decrescente, dos produtores do caju para suco e da castanha-de-caju.

3.2. Nível tecnológico por participação de mercado: principais tecnologias e falhas do sistema de produção

Para medição do nível tecnológico da cajucultura cearense foram consideradas oito tecnologias, a saber: tecnologia de preparo do terreno, tecnologia de seleção de mudas, tecnologia de cultivo, tecnologia de irrigação, tecnologia de manejo, tecnologia de colheita, tecnologia de póscolheita e tecnologia de controle de pragas e doenças. Foram, ainda, definidas a média do índice geral de tecnologia ( $I G M$ ), por segmento de mercado, e a média do índice geral de tecnologia, for grupo total de propriedades, nos três mercados analisados $\left(I G M_{s}\right)$.

Dessa forma, o objetivo desta seção é apresentar o nível de adoção das tecnologias nas propriedades rurais por segmento de mercado $\left(I_{b}\right)$, ocasião em que são apontadas as fortalezas e fraquezas mediante o cálculo do $I G M$, conforme os modelos de exploração dos cajueiros em cada segmento analisado.

\footnotetext{
${ }_{10}$ Iracema (Bond), Resibras, Cascaju (Édson Queiroz), Empesca (Amêndoas do Brasil), Cione, Irmãos Fontenele (faccionada Olam) e Agroindustrial Gomes (faccionada Olam) em Fortaleza e Cascaju (Édson Queiroz) em Cascavél.
} 
A Figura 1 resume as oito tecnologias selecionadas para medir o nível tecnológico das plantações de cajueiros inseridas nos mercados de caju para suco, caju-de-mesa e castanha-de-caju, no estado do Ceará. Os índices $I 1, I 2, I 3, I 4, I 5, I 6, I 7$ e $I 8$ representam as tecnologias preparo do terreno, seleção de mudas, cultivo, irrigação, manejo, colheita, póscolheita e controle de pragas e doenças, respectivamente. Todas as igualdades de média foram testadas a 5\% de significância, pelo método de Sheffé.

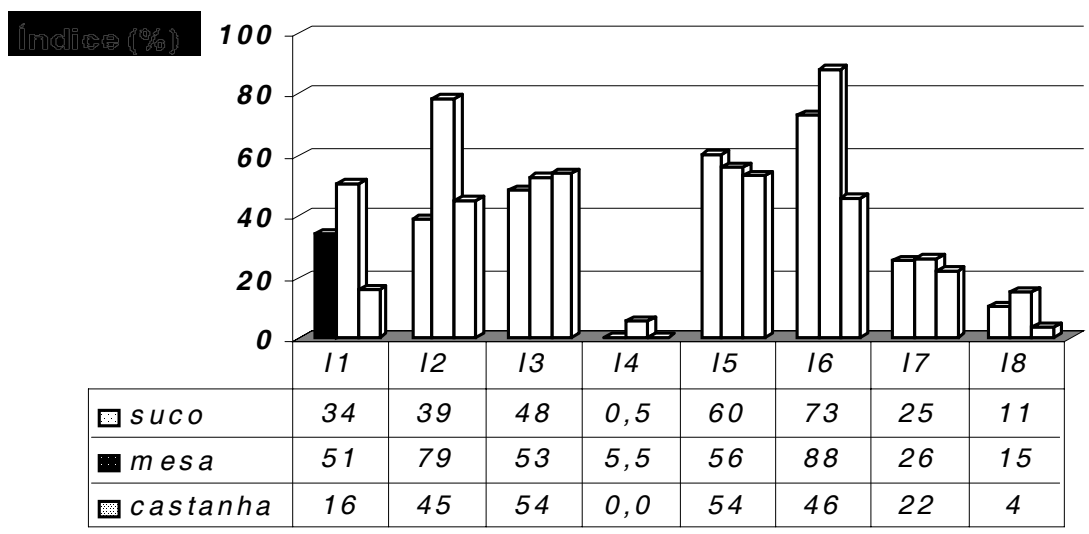

Figura 1 - Índices tecnológicos da produção do caju por segmento de mercado, segundo diferentes tecnologias.

O índice tecnológico de preparo do terreno (I1), identificado no sistema de produção do caju para suco (34\%), é idêntico ao encontrado no sistema de produção do caju-de-mesa (51\%), a 5\% de significância. Isso sugere que ambos os sistemas dispõem de padrão tecnológico entre regular e bom $(0,25<I 1 \leq 0,75)$. Ao mesmo tempo, o sistema de produção com foco na castanha-de-caju só empregava $16 \%$ da tecnologia ótima de preparo do terreno, assumindo padrão IV de tecnologia $(I 1 \leq 0,25)$. 
Os valores percentuais de 39, 79 e $45 \%$ como proporção da seleção ideal de mudas, nos mercados analisados, revelam a tecnologia I $2 \mathrm{com}$ resultados preocupantes para a produtividade futura da cajucultura, nos mercados de suco e castanha. O sistema de produção do caju-de-mesa foi o único que mostrou desempenho superior ao nível de probabilidade de 0,05 , exibindo padrão I de tecnologia, com mais de $75 \%$ da tecnologia recomendada. A tecnologia de cultivo mostrou igual nível tecnológico nas plantações dos três segmentos analisados, a 5\%. Desse modo, podese afirmar que os três modelos de produção empregam um padrão tecnológico de regular a bom $(0,25<I 3 \leq 0,75)$.

Com relação ao índice de tecnologia de irrigação, o sistema de produção do caju-de-mesa foi o único em que se identificaram métodos de irrigação mais sofisticados, a 0,05 de probabilidade. Entretanto, todos os modelos de produção apresentaram padrão insuficiente de tecnologia $(I 4 \leq 0,25)$. Os índices referentes à tecnologia de manejo (I5) também apresentaram um conjunto de valores iguais a 5\% de significância, nos três mercados analisados. Contudo, a tecnologia de manejo, praticada nos três modelos, emprega um nível tecnológico considerado bom, conforme o padrão de tecnologia $(0,50<15 \leq 0,75)$.

Quanto à colheita, o melhor nível tecnológico é adotado pelos produtores envolvidos com o caju-de-mesa, aproximadamente $88 \%$ da tecnologia recomendada. A tecnologia de colheita utilizada pelas propriedades ocupadas com o caju para suco foi explorada em $73 \%$ da recomendada, enquanto as propriedades de cajueiros focadas na exploração da castanha só utilizaram $46 \%$. As tecnologias de colheita, praticadas nas propriedades inseridas nos mercados do caju para suco e caju-de-mesa, mostraram índices idênticos a 5\%.

Na tecnologia de pós-colheita, os três sistemas de produção foram classificados com tecnologia insuficiente para o desenvolvimento da cajucultura $(I 7 \leq 0,25)$. Da mesma forma, na análise do índice 
tecnológico de controle de pragas e doenças foi identificada baixa aplicação de métodos preventivos e curativos. Conforme os índices 16, 21 e $8 \%$, nos respectivos modelos de exploração do caju estudados, esse nível de adoção é considerado insuficiente para o cultivo do cajueiro $(I 8<0,25)$.

Como mostra a Figura 2, o IGM aponta o conjunto de propriedades agrupadas na atividade de frutas frescas (caju-de-mesa) como as mais preparadas tecnologicamente, com utilização de 46,7\% das tecnologias recomendadas. Os produtores do caju para suco apresentaram posição intermediária, com uso de 36,4\% da tecnologia ideal para produção de caju, e, por último, têm-se os produtores focados na exploração da castanha, os quais empregavam $30,1 \%$ da tecnologia recomendada. A média do índice geral de tecnologia do grupo total de propriedades $\left(I G M_{s}\right)$ apresentou-se bem abaixo do recomendado, com emprego de $35,4 \%$ da tecnologia ótima.

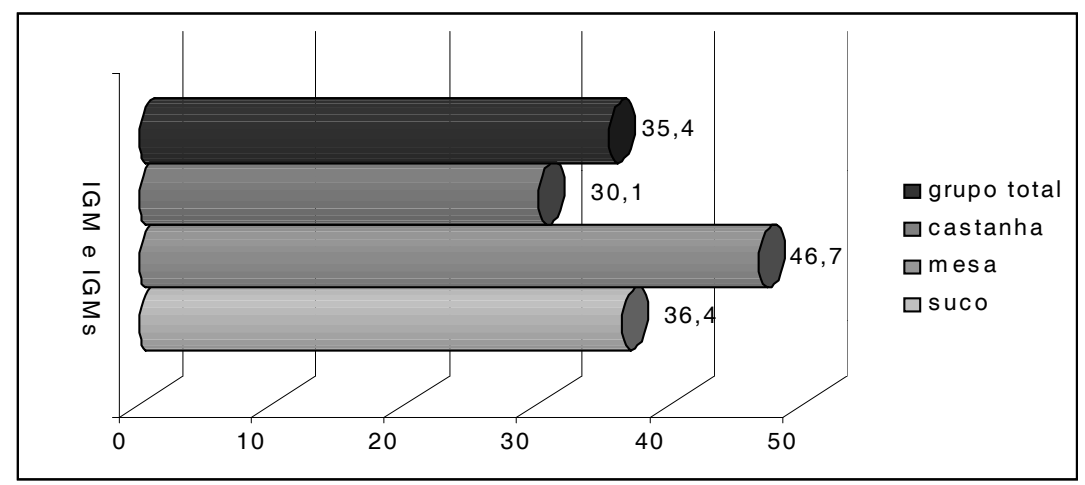

Figura 2 - Média do índice geral de tecnologia por participação de mercado e média do índice geral de tecnologia do grupo total de propriedades $I G M$. 
Conforme discriminação dos índices tecnológicos, os produtores dos três sistemas de produção estão classificados no padrão III de tecnologia, considerado um nível tecnológico regular para a atividade do caju, com utilização de menos de $50 \%$ do recomendado. No entanto, constata-se que as propriedades com melhores índices de adoção tecnológica se dedicam, inclusive, ao aproveitamento do pedúnculo de caju. Foi rejeitada hipótese de igualdade de médias a 5\% de significância, nos três índices identificados.

3.2.1. Contribuição da b-ésima tecnologia $(\mathrm{Cb})$ para a formação da média do índice geral de tecnologia (IGM ), por segmento de mercado

A Tabela 2 mostra as contribuições das respectivas tecnologias $(C b)$, por segmento de mercado. O objetivo da referida tabela é auxiliar na determinação dos pontos, fortes e fracos, do sistema produtivo da cajucultura cearense. Com relação às principais tecnologias para formação do $I G M$, o diferencial entre os sistemas de produção comparados é identificado no conjunto de estabelecimentos rurais organizados para o mercado de frutas frescas. O cuidado com a seleção de mudas, sob a responsabilidade da segunda principal tecnologia na composição do $I G M$, é, em qualquer aspecto, uma característica determinante para o sucesso produtivo das plantas. 
Sergiany da Silva Lima, Ahmad Saeed Khan, Patrícia Sales Lima,

Lucas Antônio de Sousa Leite \& Adriano Lincoln Albuquerque Mattos

Tabela 2 - Contribuição das tecnologias para a formação do , por segmento de mercado

\begin{tabular}{l|c|c|c}
\hline \multirow{2}{*}{ Tecnologia de produção do cajueiro anão-precoce } & \multicolumn{3}{|c}{ Segmento } \\
\cline { 2 - 4 } & Suco & Mesa & Castanha \\
\hline Tecnologia de preparo do terreno & 0,043 & 0,063 & 0,020 \\
Tecnologia de seleção de mudas & 0,048 & $\mathbf{0 , 0 9 8}$ & 0,057 \\
Tecnologia de cultivo & 0,060 & 0066 & $\mathbf{0 , 0 6 8}$ \\
Tecnologia de irrigação & 0,001 & 0,007 & 0,000 \\
Tecnologia de manejo & $\mathbf{0 , 0 7 5}$ & 0,070 & $\mathbf{0 , 0 6 7}$ \\
Tecnologia de colheita & $\mathbf{0 , 0 9 2}$ & $\mathbf{0 , 1 1 0}$ & 0,058 \\
Tecnologia de pós-colheita & 0,032 & 0,032 & 0,027 \\
Tecnologia de controle de pragas e doenças & 0,014 & 0,019 & 0,005 \\
\hline$I G M$ & 0.364 & 0,467 & 0,301 \\
\hline
\end{tabular}

Fonte: Dados da pesquisa.

Como atestaram Cavalcanti et al. (2000), o emprego da seleção precoce de mudas constitui uma técnica que vem recebendo bastante atenção, dada a simplicidade metodológica na propagação vegetativa e dados os resultados comprovados em programas de melhoramento do cajueiro anão-precoce. Quanto às tecnologias de menor representação na formação do $I G M$, as tecnologias de irrigação e controle de pragas e doenças constituem as principais falhas do sistema produtivo de caju na região analisada.

\subsection{Fatores determinantes na adoção de tecnologia nas plantações de cajueiro do Estado}

Uma apresentação preliminar do modelo utilizado nesta pesquisa, para identificar as variáveis que influenciam a probabilidade de um maior nível tecnológico, aponta sete variáveis estatisticamente significativas a 0,05 de probabilidade, quais sejam, areagiga, areapreco, acecredt, cjatvdprinc, associação, p_cast e p_pedun, como mostra a Tabela 3. Apenas a variável escolaridade não foi significante. 
Tabela 3 - Coeficientes e efeitos marginais dos principais fatores de influência na probabilidade de adoção tecnológica na cajucultura cearense, modelo Logit

\begin{tabular}{ccccc}
\hline adtec & Coeficientes & p-valor & $\begin{array}{c}\text { Efeitos marginais } \\
(\mathbf{d y} / \mathbf{d x})\end{array}$ & p-valor \\
\hline areagiga & $-0,0358036$ & 0,011 & $-0,0076559$ & 0,010 \\
areapreco & 0,125319 & 0,004 & 0,0267971 & 0,000 \\
acecredt & 1,422128 & 0,002 & - & - \\
cjatvdprinc & 1,515579 & 0,022 & - & - \\
associação & 1,35863 & 0,004 & - & - \\
escolaridade & 0,173112 & 0,396 & $-0,0370168$ & 0,389 \\
p_cast & 0,025926 & 0,045 & 0,0055438 & 0,049 \\
p_pedun & 0,1242854 & 0,011 & 0,0265761 & 0,009 \\
constante & $-5,915882$ & 0,000 & - & 0,000 \\
Número de obs. & & & & 157 \\
Pseudo R ${ }^{2}$ & & & & 0.3489 \\
Prob(LR statistic) & & & & 0,000 \\
\hline Fonte: Elaborado pelo
\end{tabular}

Fonte: Elaborado pelo autor.

O Pseudo $\mathrm{R}^{2}$ explica que a variação de todas as variáveis exógenas, em conjunto, responde por $34,89 \%$ da variação na probabilidade de adoção tecnológica. A grandeza responsável pelo poder de predição do modelo indica que, de todas as previsões feitas pelo modelo, aproximadamente $69 \%$ efetivaram-se, fator que levou à opção pela utilização do Logit. Como discutido na seção do método de análise, a decisão sobre o melhor modelo de resposta a ser empregado em estudos de resposta binária é arbitrária. Contudo, Oliveira (2003) empregou o critério de variáveis significativas para a decisão sobre o modelo de resposta utilizado. Já Vicente (1998) considerou, para a seleção do modelo, os indicadores de qualidade do ajuste como nível de significância das variáveis, percentual de classificação de respostas corretas e Pseudo $\mathrm{R}^{2}$.

A interpretação dos resultados da regressão esclarece, com maior nitidez, os motivos atribuídos à diferenciação da tecnologia média identificada nos sistemas de produção dos três mercados analisados. Entretanto, dada a limitação do Logit com relação a variáveis não-métricas, o máximo de 
informações que os coeficientes das variáveis "acecredt, cjatvdprinc e associação" poderão fornecer é quanto à direção da relação entre elas e a adoção tecnológica.

Assim, para cada aumento de 1 hectare de área plantada com cajueiro gigante, existe probabilidade negativa de 0,76 pontos percentuais sobre a adoção de tecnologia. Esta relação inversa é justificada pelo fato de a plantação de cajueiro gigante ser praticada, tradicionalmente, de forma rudimentar, sem o uso de tecnologias, ou seja, a plantação de cajueiro gigante é a própria ausência de tecnologia. Já variações na área plantada com cajueiro precoce conferem uma influência positiva na probabilidade de adoção de tecnologia de 2,67 pontos percentuais para cada hectare adicional, uma vez que o cajueiro-anão precoce já é parte da tecnologia recomendada para cultura.

A variável condizente com a disponibilidade de crédito usufruída pelas unidades produtivas constitui outra fonte de influência positiva na probabilidade de decisão acerca da adoção de tecnologia. De acordo com sinal do coeficiente da variável "acecredt", as unidades produtivas com acesso a fontes de financiamento estão predispostas a adoções tecnológicas. $\mathrm{O}$ mesmo resultado pode ser encontrado no trabalho de Oliveira (2005).

Conforme o valor do coeficiente da variável "cjatvdprinc", verificou-se que, em organizações produtivas que têm o caju como principal atividade, a probabilidade de adoção tecnológica é influenciada positivamente. Esse resultado pode ser encontrado também em Oliveira (2005). Verificou-se, ainda, que organizações de produtores que integram associações que participem ativamente da compra de insumos e, ou, da venda dos produtos da cajucultura constituem sistemas produtivos potencialmente habilitados para adoção de tecnologia. Resultado similar foi encontrado por Monte e Teixeira (2006).

A variável escolaridade não foi identificada como significante para adoção de tecnologia a 0,1 de probabilidade. Possivelmente, esse resultado esteja 
ligado à baixa escolaridade identificada como característica comum para a maioria dos produtores do Estado, particularidade esta denominada, em Gujarati (2000), variabilidade insuficiente dos regressores, vindo a comprometer a estimação do parâmetro. A variável escolaridade apresenta-se como significativa na adoção tecnológica em diversos trabalhos, como exibido em Oliveira (2005) e em Monte e Teixeira (2006).

As variáveis de preço por quilograma da castanha e do pedúnculo de caju também se firmaram como valores bastante significativos para explicação do processo de adoção tecnológica. O preço da castanha, segundo a interpretação do seu efeito marginal, demonstra que, para variação de um centavo de real no preço do quilograma, a probabilidade de o produtor adotar tecnologia aumenta em, aproximadamente, 0,55 pontos percentuais. O preço do quilograma de pedúnculo constituiu a variável de maior efeito marginal significativo no processo de adoção de tecnologia. Conforme sua interpretação, espera-se um efeito positivo de, aproximadamente, 2,65 pontos percentuais sobre a probabilidade de adoção tecnológica para variação de um centavo de real no preço do quilograma de pedúnculo.

O teste de heterocedasticidade, realizado pelo método descrito por Davidson e Mackinnon do Soft Eviews 6, não rejeitou a hipótese nula de homocedasticidade, a 5\% de significância. O nível de correlação, segundo os coeficientes de Pearson e Spearman's, para as referidas variáveis paramétricas e não-paramétricas do modelo ficou abaixo de 0,6, considerado pouco importante para representar problemas de multicolinearidade (GUJARATI, 2000). 
Sergiany da Silva Lima, Ahmad Saeed Khan, Patrícia Sales Lima, Lucas Antônio de Sousa Leite \& Adriano Lincoln Albuquerque Mattos

\section{Conclusões}

A análise do perfil socioeconômico dos produtores rurais de caju do Estado aponta um conjunto de agentes com características bastante homogêneas. Nas observações que tratam do nível educacional, descreve-se a maioria dos produtores como analfabetos ou pessoas que não chegaram a concluir o ensino fundamental. A mão-de-obra familiar constitui a principal fonte da força de trabalho ocupada nas propriedades de cajueiros e é utilizada, especialmente, durante os períodos de limpa do cajueiro e colheita do caju. A maior parte dos produtores mostrou-se vulnerável às imposições dos mercados consumidores, salvo os produtores inseridos no mercado de frutas frescas. A grande maioria manifestou-se completamente dependente dos serviços de intermediários. Esse conjunto de fatores refletiu, diretamente, no nível de preço praticado na porteira da propriedade. Mesmo assim, observou-se que o ganho com os produtos da cajucultura representa a maior fonte de renda das famílias, valendo observar que esse perfil é mais evidente entre os produtores que conseguem aproveitar todo o caju.

No Ceará, a tecnologia identificada na produção de caju foi classificada como regular, com a adoção de $35,4 \%$ do recomendado. Entre os três segmentos estudados, a adoção tecnológica dos produtores do caju-demesa compreende a melhor posição com o uso de $46,7 \%$ do recomendado. Os modelos de produção, adotados pelos produtores de caju, para suco e castanha empregavam 36,4 e 30,1\% do ótimo, respectivamente. As características socioeconômicas relevantes na determinação do nível tecnológico das plantações de cajueiros, no estado do Ceará, foram área plantada com cajueiro gigante; área plantada com cajueiro precoce; acesso ao crédito; cajucultura como atividade principal; associação e preços da castanha e do pedúnculo. Destes, apenas a área plantada com cajueiro gigante afetava, negativamente, a probabilidade de adoção tecnológica. Os preços do quilograma da castanha e do pedúnculo foram considerados as variáveis de maior influência na probabilidade de adoção tecnológica. Entretanto, os melhores preços foram 
identificados no mercado do caju-de-mesa, que apresentou vantagem expressiva frente aos preços verificados nos demais mercados.

\section{Referências}

BARROS, L. M. (editor Técnico). Caju. Produção: aspectos técnicos. Embrapa Agroindústria Tropical (Fortaleza, CE). - Brasília: Embrapa Informação Tecnológica, 148 p.; (Frutas do Brasil; 30). 2002.

CAJUCUlTURA. História do Cajueiro. Disponível em < $\underline{\text { http:// }}$ www.cajucultura.com.br/ > acesso em 27/01/2008.

CAVALCANTI, J. J. V.; PAIVA, J. R.; BARROS, L. M.; CRISÓSTOMO, J. R.; CORRÊA, M. P. F. Repetibilidade de Características de Produção e Porte da Planta em Clones de Cajueirosanão precoce. Pesquisa Agropecuária brasileira, Brasília, v. 35, n. 4, p. 773 - 777, abr. 2000.

DAMASCENO JÚNIOR, J. A.; BEZERRA, F. C. Qualidade de Pedúnculo de Cajueiro-Anão-precoce Cultivado Sob Irrigação e Submetido a Diferentes Sistemas de Condução e Espaçamento. Revista Brasileira de Fruticultura, Jaboticabal - SP, v. 24, n. 1, p. 258-262, abr. 2002.

FIGUEIRÊDO JUNIOR, H. S. Desafios Para a Cajucultura no Brasil: O Comportamento da Oferta e da Demanda da Castanha de Caju. Revista Econômica do Nordeste, Fortaleza, v. 37, nº 4, out-dez. 2006.

Food and Agriculture Organization (FAO) - Exportação de castanha de caju sem casca. Disponível em < www.fao.org > acesso em 10/01/ 2010.

GREENE, W. H. Econometric Analyses. 3. Ed. New Jersey: Prentice Hall, 1997. 
Sergiany da Silva Lima, Ahmad Saeed Khan, Patrícia Sales Lima, Lucas Antônio de Sousa Leite \& Adriano Lincoln Albuquerque Mattos

GUJARATI, D. N. Econometria Básica. Terceira edição, São Paulo: Makron Books. 2000.

HAIR, Jr., J.F, R.E. ANDERSON, R.L. TATHAM, W. C. B. trad. Adonai Schlup Sant'Anna e Anselmo Chaves Neto . Análise Multivariada de dados - 5. ed. - Porto Alegre: Bookman, 2005.

IBGE - Instituto Brasileiro de Geografia e Estatística Levantamento Sistemático da Produção Agrícola - LSPA 2005/06. Disponível em < http://www.ibge.gov.br > Acesso em 27/02/2006.

IBGE - Instituto Brasileiro de Geografia e Estatística - Censo Agropecuário Brasileiro. Disponível em $<$ http://www.ibge.gov.br $>$. Acesso em 15/06/2008.

LEITE, L. A. de S.; PAUlA PESSOA, F. A. P. Aspectos Socioeconômicos. In: BARROS, L. de Moura (Org.). Caju, Produção: Aspectos Técnicos. Embrapa Agroindústria Tropical (Fortaleza, CE). - Brasília: Embrapa Informação Tecnologia, 148 p.; (Frutas do Brasil; 30). 2002.

MARTINS, G.; COSTA L. M. C. Comportamento da área plantada, produção e rendimento da castanha do caju no Estado do Ceará, no período de 1958 a 2001. Humanidades, Fortaleza, v. 20, n. 2, p. 130134. jul./dez. 2005.

MENDONÇA, T. G. LÍRIO, V. S. GOMES, M. F. M. CAMPOS, A. C. Inserção do Brasil no mercado mundial de castanha de caju no período de 1990 a 2005. Revista Econômica do Nordeste, Volume 40, $N^{\circ} 01$, jan./mar. 2009.

MONTE, E. Z.; TEIXEIRA, E. C. Determinantes da Adoção da Tecnologia de Despolpamento na Cafeicultura. Revista de Economia e Sociologia Rural, Rio de Janeiro. vol. 44, nº 02, p. 201-217, abr/jun 2006 - Impressa em junho de 2006. 
MORAIS, A. S.; MAIA, G. A.; FIGUEIREDO, R. W.; ALVES, R. E.; FILGUEIRAS, H. A. C.; MOURA, C. F. H. Armazenamento Refrigerado sob Atmosfera Modificada de Pedúnculos de Cajueiro-AnãoPrecoce dos Clones CCP-76, END-157, END-183 E END-189. Revista Brasileira de Fruticultura, Jaboticabal - SP, v. 24, n. 3, p. 647-650, dezembro 2002.

OLIVEIRA, M. A. S. KHAN, A. S. LIMA, P. V. P. S. Adoção Tecnológica e seus condicionantes: o caso da bananicultura no pólo CaririCe. Revista de Economia e Agronegócio, vol. 3, nº 3, 2005.

OliveirA, M. A. S. Nível Tecnológico e Seus Fatores Condicionantes na Bananicultura do Município de Mauriti-CE. 2003. 92 f. Dissertação (Mestrado em Economia Rural) - Centro de Ciências Agrícolas, Universidade Federal do Ceará, Fortaleza, 2003.

OLIVEIRA, V. H. Cultivo do Cajueiro Anão-precoce, Fortaleza: Embrapa Agroindústria Tropical, 2002.

PAULA PESSOA, P. F. A.; OLIVEIRA, V. H;. SANTOS, F. J. S.; SEMRAU, L. A. S. Análise da Viabilidade Econômica do Cultivo do Cajueiro Irrigado e Sob Sequeiro. Revista Econômica do Nordeste, Fortaleza, v. 31, n. 2 p. 178-187, abr-jun. 2000.

PINHO, F. A. Modelos de Decisão Binários: Uma Revisão. Revista de Economia Agrícola, São Paulo, v. 54, n. 1, p. 43-57, jan/jun, 2007.

VICENTE, J. R. Determinantes da Adoção de Tecnologia na Agricultura Paulista. Estudos Econômicos, SÃO PAULO, V. 28, N. 3, P. 421-451, JULHO-SETEMBRO, 1998. 
Abstract: This paper analyses the technological adoption process in culture of cashew from Ceará. To reach this objective a survey was made from producers located in Ceará. As for measuring the technological level of producers were analyzed variables related to the practices of the system of culture of cashew. Moreover, we estimated the coefficients of the variables that influence the likelihood of technology adoption by regression function Cumulative Distribution Logistics Standard (Logit). It was observed that the farms occupied by the in nature cashew has the best technology level, using the recommended $46.7 \%$, while those occupied with cashew for nuts and juice use only 36.4 and $30.1 \%$, respectively. The access to credit, the price of nuts and the peduncle were the main factors decision of technological adoption process in culture of cashew from Ceará.

Keywords: crop cashew, technological level, adoption technology. 